\title{
ACOLHIMENTO À FAMÍLIA DE NEONATOS INTERNADOS EM UNIDADE DE TERAPIA INTENSIVA: UMA REVISÃO INTEGRATIVA DA LITERATURA
}

\section{WELCOMING TO THE FAMILY OF NEONATES ADMITTED TO THE INTENSIVE CARE UNIT: AN INTEGRATIVE LITERATURE REVIEW}

\author{
Crisley Ferraz Araújo ${ }^{1} *$ Juliana Xavier Pinheiro da Cunha ${ }^{2} *$ Livia dos Santos Mendes $^{3} *$ \\ Chrisne Santana Biondo ${ }^{4}$
}

\begin{abstract}
RESUMO
Objetivo: Analisar as evidências científicas sobre o acolhimento realizado pela equipe de saúde aos familiares de neonatos internados em Unidade de Terapia Intensiva Neonatal (UTIN). Metodologia: Realizou-se uma revisão integrativa da literatura nas bases de dados LILACS, MEDLINE, BDENF e literatura cinzenta, de artigos publicados entre os anos 2010 e 2020, nos idiomas inglês, espanhol e português, que abordassem a temática do estudo. Resultados: Para a análise dos 9 artigos selecionados, foi utilizada a categorização, através da análise temática de conteúdo, emergindo três categorias: os benefícios do acolhimento à família na UTIN; entraves para a efetivação do acolhimento; e a empatia norteando o acolhimento. Verificou-se que o acolhimento realizado pela equipe de saúde gera benefícios à família, como o alívio de medos e ansiedades, a manutenção dos laços afetivos do familiar com o neonato, a participação nos cuidados e na tomada de decisão. Além disso, faz com que o ambiente da terapia intensiva se torne menos hostil e ameaçador. A comunicação adequada permite que o familiar se aproxime da equipe e expresse suas angústias, assim, ações empáticas e acolhedoras dos profissionais de saúde tornam o período de internação para a família menos doloroso. Porém, normas e rotinas da unidade, sobrecarga de trabalho dos profissionais, além do foco da equipe exclusivo no neonato, fazem com que o acolhimento à família não se efetive de forma adequada. Conclusão: $O$ acolhimento realizado pelos profissionais de saúde às famílias nas UTIN se revelou um fator benéfico para a redução de sentimentos negativos relacionados à internação do neonato.
\end{abstract}

Palavras-chave: Família; Acolhimento; Unidade de Terapia Intensiva Neonatal.

\begin{abstract}
Objective: To analyze the scientific evidence on the effects of the reception performed by the health team on family members of neonates admitted to a Neonatal Intensive Care Unit (NICU). Methodology: An integrative literature review was carried out in the LILACS, MEDLINE, BDENF and grey literature databases, of articles published between 2010 and 2020, in English, Spanish and Portuguese and that addressed the study theme. Results: From the analysis of the nine selected articles, categorization was used, through thematic content analysis, emerging three categories were established for discussion: the benefits of welcoming the family at the NICU; obstacles to effective reception; and empathy guiding the welcoming. It was found that the reception performed by the health team generates benefits to the family, such as the relief of fears and anxieties, maintenance of the emotional bonds of the family member with newborns, participation in care and decision making. In addition, it makes the intensive care environment less hostile and threatening. Adequate communication allows the family member to approach the team and express their anxieties and empathetic and welcoming actions by health professionals make the hospitalization period for the family less painful. However, the unit's norms and routines, the professionals' work overload, in addition to the exclusive team's focus on the newborn, make the welcoming to the family not to take place properly. Conclusion: The reception performed by health professionals to families in the NICUs proved to be a beneficial factor for reducing negative feelings related to the neonate's hospitalization.
\end{abstract}

Key words: Family; Embracement; Neonatal Intensive Care Unit.

\footnotetext{
${ }^{1}$ Enfermeira graduada pela Universidade Federal da Bahia. Email: ferrazcrisley@ gmail.com. https://orcid.org/0000-0001-5236-7830

${ }^{2}$ Enfermeira, doutoranda em epidemiologia pela Universidade Federal do Rio Grande do Sul (UFRGS), professora assistente da Universidade Federal da Bahia-UFBA. Email: julianaxcunha@gmail.com Orcid: https://orcid.org/0000-0002-3752-206X

${ }^{3}$ Enfermeira, mestre em saúde coletiva pela Universidade Federal da Bahia-UFBA. Enfermeira assistente da Unidade de Terapia Intensiva Adulto do Hospital Geral de Vitória da Conquista Email: liviaenfuesb@yahoo.com.br Orcid: https://orcid.org/0000-0001$\underline{6053-8484}$

${ }^{4}$ Enfermeira, doutoranda em ciências da saúde pela Universidade Estadual do Sudoeste da Bahia-UESB, professora assistente da Universidade Federal da Bahia-UFBA.Email: tity_biondo_enf@hotmail.com Orcid: https://orcid.org/0000-0002-0583-5491
} 


\section{INTRODUÇÃO}

A descoberta de uma gestação traz consigo grandes mudanças e adaptações ao núcleo familiar, e o desenvolvimento do vínculo à criança se estabelece antes mesmo do seu nascimento. Muitas idealizações positivas são construídas em torno do recémnascido e quando este necessita de cuidados intensivos, logo após o seu nascimento, o emocional da família é afetado. Além dos prejuízos emocionais, ocorrem interferências nos aspectos sociais, econômicos e na dinâmica familiar, contribuindo para que todo esse processo de internação em uma Unidade de Terapia Intensiva Neonatal (UTIN) gere, na família, sentimentos de angústia ${ }^{(1-2)}$.

A UTIN é composta por uma série de aparatos tecnológicos e equipe multiprofissional especializada, com o objetivo de promover a recuperação através de um cuidado em saúde avançado ao neonato. No entanto, mesmo a família compreendendo a real necessidade de internação para cuidados intensivos, o ambiente da UTIN, por conta de toda representação social que o envolve, desperta sentimentos negativos, relacionados à morte. Isso porque a UTIN é vista como um ambiente hostil, desumano, frio, local de extremo sofrimento e que gera a quebra do vínculo familiar ${ }^{(2-4)}$.

Sendo assim, acolher essas famílias na UTIN é essencial, visto que o processo de acolhimento oportuniza novos sentimentos relacionados ao vínculo gerado com a equipe de saúde, reduzindo o medo, a sensação de desamparo e impotência. Ao praticar o acolhimento, a equipe de saúde desenvolve uma assistência humanizada, que não é apenas centrada no paciente, mas considera a sua família na relação do cuidado. Como consequência, o familiar se sente à vontade para expressar suas angústias e dúvidas, favorecendo até mesmo a sua participação nos cuidados básicos ao paciente ${ }^{(2,4-6)}$.

O Ministério da Saúde (MS), conforme os princípios do Sistema Único de Saúde (SUS) e da Política Nacional de Humanização (PNH), sancionada no ano de 2011, preconiza uma assistência humanizada e integral, abrangendo os cuidados físicos, emocionais e espirituais prestados ao paciente e a sua rede de apoio familiar. Traz o acolhimento como prática primordial para a assistência, embasada na escuta qualificada e ativa, comunicação efetiva, possibilitando, assim, a construção de uma relação de confiança entre profissionais e familiares, no intuito de reduzir os impactos e sentimentos negativos desencadeados pela internação de um neonato em uma UTIN ${ }^{(6-9)}$.

No entanto, apesar da importância atribuída ao acolhimento, foi verificada, durante a busca por estudos nas bases de dados, uma baixa quantidade de publicações nos últimos 10 anos. Além disso, os estudos que abordavam o acolhimento, em sua maioria, focavam no acolhimento materno, sem envolver seu contexto familiar. $\mathrm{O}$ objetivo era utilizar o acolhimento para favorecer melhorias na assistência física ao neonato, a exemplo da abordagem do aleitamento materno e do método canguru, em que não era discutida a subjetividade materna e o suporte familiar para apoio à manutenção da saúde do neonato. Perante o exposto, verifica-se a importância de se pesquisar sobre os efeitos do acolhimento à família na UTIN para que a equipe de saúde possa considerar a família no cuidado integral ao paciente.

Frente a isso, questiona-se: Quais as evidências científicas sobre o acolhimento realizado pela equipe de saúde aos familiares de neonatos internados em UTIN? Assim, este 
estudo teve como objetivo analisar as evidências científicas sobre o acolhimento realizado pela equipe de saúde aos familiares de neonatos internados em Unidade de Terapia Intensiva Neonatal (UTIN).

\section{METODOLOGIA}

Trata-se de uma revisão integrativa da literatura, que se refere a uma análise ampliada de artigos que levaram a reflexões para o presente estudo. Ela é utilizada para identificar e unir estudos independentes que tratam da mesma temática, permitindo conectar os novos conhecimentos sobre o assunto, além de proporcionar uma base para decisões, a fim de auxiliar na melhoria da prática clínica, indicando, também, pontos sobre os quais são necessários mais estudos (10).

Foram definidas algumas etapas para viabilizar a realização desta revisão, quais sejam: 1- definição da temática a ser pesquisada; 2- formação da pergunta norteadora; 3- escolha da base de dados; 4definição dos descritores e estratégias de busca; 5- criação dos critérios de exclusão e inclusão; 6- busca na base de dados definida; 7- avaliação dos trabalhos encontrados ${ }^{(11)}$.

A questão norteadora desta revisão foi formulada utilizando-se a estratégia PICO, que infere a $\mathrm{P}$ - população, I- intervenção, Ccomparação e O- desfecho ou resultado. Vale salientar que, em função de este estudo não ter como foco pesquisas clínicas, não foi considerado o item $\mathrm{C}$ para a construção da pergunta do estudo ${ }^{(12)}$. Sendo assim, foi estruturado da seguinte forma: P- Familiares de neonatos internados na unidade de terapia intensiva neonatal; I- Acolhimento realizado pela equipe de saúde na UTI neonatal; C- não se aplica; e O- Efeitos do acolhimento.
A busca dos artigos foi realizada no mês de abril de 2020, utilizando-se termos que se aproximavam da temática em estudo, presentes na relação de Descritores em Ciências da Saúde, criados pelo Centro Latino-Americano de Informação em Ciências da Saúde (DeCS/BIREME): "Família", "Unidade de Terapia Intensiva Neonatal" e "Acolhimento". Foi utilizado o operador booleano "AND", que favoreceu o cruzamento dos termos para a busca. As bases de dados utilizadas foram: Latina Americana e do Caribe em Ciências Em Saúde (LILACS), Medical Literature Analysis and Retriveal System Online (MEDLINE); Banco de Dados em Enfermagem (BDENF) e base de dados cinzentas (google acadêmico e busca nas referências dos estudos primários $\mathrm{e}$ secundários identificados).

Foram definidos os seguintes critérios de inclusão: artigos originais, publicados entre os anos de 2010 e 2020, escritos nas línguas português, inglês e espanhol e que abordassem a temática do estudo. Foram excluídos: teses, dissertações, projetos, revisões de literatura, documentos sem disponibilização de resumo ou documento na íntegra, artigos duplicados e que não respondessem à questão norteadora. Com a aplicação das estratégias, foram encontrados 1344, destes, 1331 foram excluídos, sendo 232 duplicados, 871 por não atenderem à questão norteadora, 52 por não possuírem resumo, 150 por se tratar de teses ou revisões de literatura, e 19 por publicação em outra língua. Após leitura completa dos artigos, 11 foram excluídos por não atenderem ao objetivo do trabalho. Desta forma, foram incluídos como amostra desta revisão 9 artigos, conforme pode ser visualizado no fluxograma de seleção dos artigos, baseado no modelo PRISMA (Figura 1). 
Figura 1- Fluxograma de seleção dos artigos para a revisão de literatura acerca do acolhimento da equipe de saúde à família de neonatos internados na unidade de terapia intensiva neonatal, baseado no modelo PRISMA ${ }^{(13)}$.

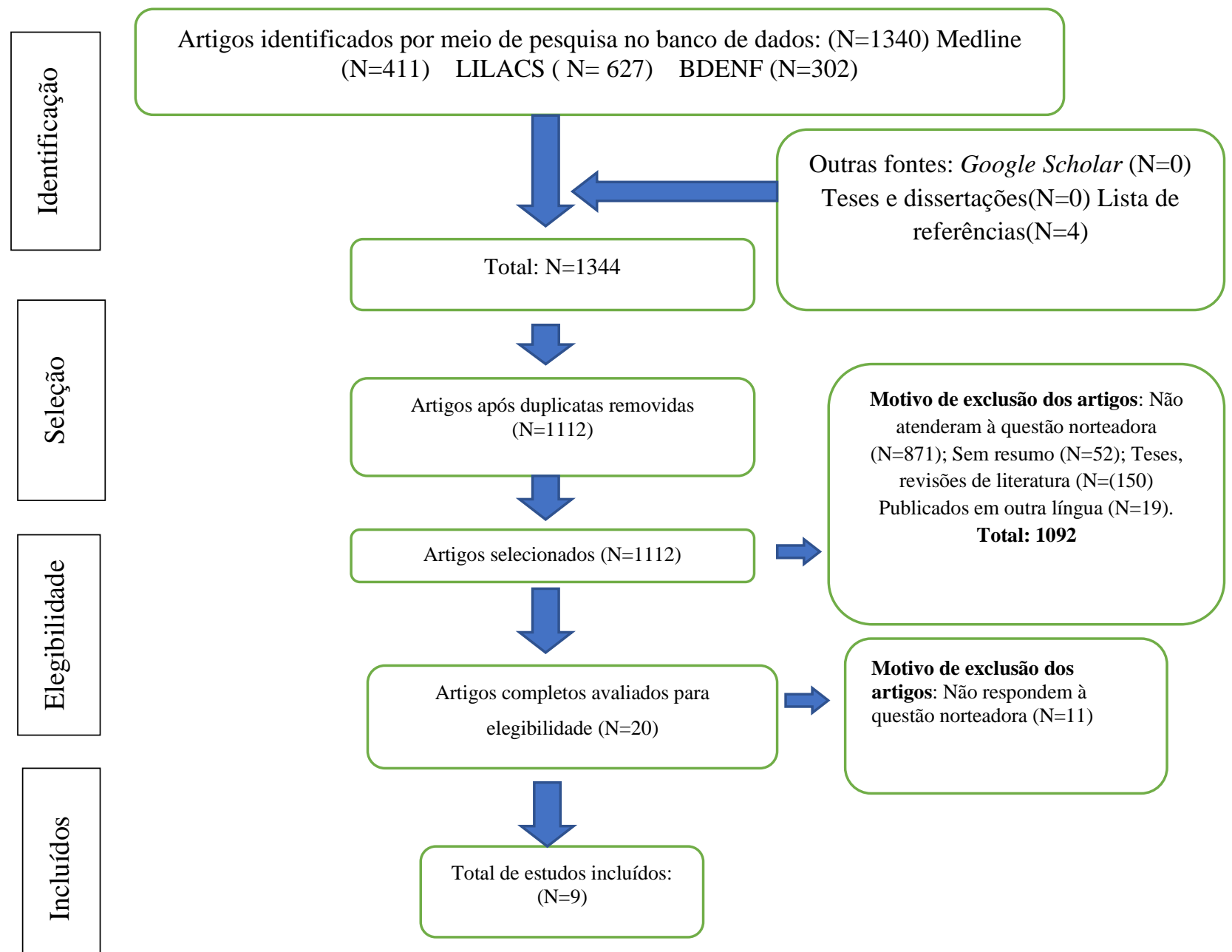

Fonte: Os autores

Após a seleção e a observação dos dados obtidos, a partir da categorização através da análise temática de conteúdo, os artigos foram organizados conforme o ano de publicação, a revista na qual o documento foi publicado, bem como título, autores, objetivos, a fim de se definir o seu nível de evidência. A hierarquização dos documentos se deu por meio de sete níveis: 1- revisões integrativas ou metanálise de ensaios clínicos; 2- comprovação de, ao menos, um ensaio clínico controlado com boa delimitação; 3ensaios clínicos delimitados e não randomizados; 4- pesquisas de coorte e casocontrole com boa delimitação; 5- revisões integrativas de pesquisas descritivoqualitativos; 6- evidências derivadas de um único estudo descritivo ou qualitativo; e 7avaliação de autoridades ou delegações especializadas, atribuindo interpretações baseadas para além da pesquisa ${ }^{(14)}$.

De acordo com a Lei de Direitos Autorais, Lei $\mathrm{n}^{\circ} 12.853$, de 14 de agosto de 2013, esta pesquisa obedeceu às determinações ética, respeitando os direitos autorais dos documentos coletados. Por se 
tratar de uma revisão integrativa, o presente estudo não necessita de aprovação em comitê de ética ${ }^{(15)}$.

\section{RESULTADOS}

Após a definição das etapas para viabilizar o estudo, juntamente com a formulação da questão norteadora, a partir da estratégia do PICO, foi iniciada a busca nas bases de dados, o que totalizou 1344 artigos. Após o emprego dos critérios de inclusão e exclusão, foram selecionados 9 artigos que responderam à questão norteadora e que fizeram parte da construção do presente estudo.

Dos 9 artigos selecionados, $n=3(33,3 \%)$ se encontravam na base de dados BDENF, $\mathrm{n}=01(11,1 \%)$ no LILACS, $\mathrm{n}=01(11,1 \%)$ na MEDLINE e $\mathrm{n}=04 \quad(44,5 \%)$ foram encontrados na literatura cinzenta. Com relação ao ano de publicação, $\mathrm{n}=2(22.2 \%)$ artigos foram publicados no ano de 2018, $\mathrm{n}=2$ (22.2\%) em 2011, $\mathrm{n}=01$ (11.1\%) para cada ano 2010, 2012, 2015, 2016 e 2019.

Com relação ao idioma de publicação dos artigos selecionados, $\mathrm{n}=8 \quad(88.9 \%)$ foram publicados em português e $\mathrm{n}=1(11.1 \%) \mathrm{em}$ inglês. Todos os estudos, $\mathrm{n}=9$ (100\%), correspondem a pesquisas qualitativas de caráter descritivo, sendo classificados, portanto, no nível de evidência 6 (evidências derivadas de um único estudo descritivo ou qualitativo). É possível perceber que se têm poucas publicações realizadas sobre a temática, fator que pode inferir pouco interesse dos profissionais pelotema.

A seguir, é apresentada a relação de artigos selecionados de acordo com o ano, periódico, título do artigo, autores, objetivo (Quadro 1).

Quadro 1: Artigos selecionados de acordo com o ano, periódico, título, autores e objetivos

\begin{tabular}{|l|l|l|l|l|}
\hline Ano & Periódico & Título & Autores & Objetivo \\
\hline 2010 & $\begin{array}{l}\text { Revista de } \\
\text { Enfermagem } \\
\text { UFPE }\end{array}$ & $\begin{array}{l}\text { Significado para as } \\
\text { mães de conviver com a } \\
\text { internação de um filho } \\
\text { em uma unidade de } \\
\text { terapia intensiva } \\
\text { neonatal. }\end{array}$ & $\begin{array}{l}\text { Dutra,BS, } \\
\text { Campolina,MB, } \\
\text { Arruda,TFF, } \\
\text { Lisboa,AAF, } \\
\text { Santana,JCB }\end{array}$ & $\begin{array}{l}\text { Compreender os significados para as } \\
\text { mães em conviver com um filho em } \\
\text { uma Unidade de Terapia Intensiva } \\
\text { Neonatal. }\end{array}$ \\
\hline 2011 & Elsevier & $\begin{array}{l}\text { Family support and } \\
\text { family-centered care in } \\
\text { the neonatal intensive } \\
\text { care unit: origins, } \\
\text { advances, impact. }\end{array}$ & $\begin{array}{l}\text { Gooding,JS, } \\
\text { Cooper,LG, } \\
\text { Blane,AI, } \\
\text { Franck,LS, } \\
\text { Howse,SL, } \\
\text { Bernss,SD. }\end{array}$ & $\begin{array}{l}\text { Exploramos as origens e os avanços do } \\
\text { FCC na NICU e identificamos vários } \\
\text { métodos de entrega e aspectos do FCC } \\
\text { e do apoio familiar na NICU. }\end{array}$ \\
\hline 2011 & $\begin{array}{l}\text { Epidemiologia } \\
\text { e Serviço de } \\
\text { Saúde. }\end{array}$ & $\begin{array}{l}\text { A percepção materna } \\
\text { sobre vivência e } \\
\text { aprendizado de cuidado } \\
\text { de um bebê prematuro }\end{array}$ & $\begin{array}{l}\text { Siqueira,MBC, } \\
\text { Dias,MAB }\end{array}$ & $\begin{array}{l}\text { Analisar a percepção materna sobre a } \\
\text { vivência e o aprendizado de cuidado de } \\
\text { um bebê prematuro. }\end{array}$ \\
\hline 2012 & $\begin{array}{l}\text { Texto e } \\
\text { Contexto } \\
\text { Enfermagem }\end{array}$ & $\begin{array}{l}\text { A família no cuidado } \\
\text { do recém-nascido } \\
\text { hospitalizado: } \\
\text { Possibilidades e } \\
\text { desafios para a }\end{array}$ & $\begin{array}{l}\text { Duarte,ED, } \\
\text { Sena,RR, } \\
\text { Ditiz,ES, } \\
\text { Tavares,TS, } \\
\text { Lopes,AFC, }\end{array}$ & $\begin{array}{l}\text { Analisar, a partir do cotidiano na UTIN, } \\
\text { a participação da família no cuidado ao } \\
\text { recém-nascido. }\end{array}$ \\
\hline
\end{tabular}




\begin{tabular}{|c|c|c|c|c|}
\hline & & $\begin{array}{l}\text { construção da } \\
\text { integralidade. }\end{array}$ & Silva,PM. ${ }^{(17)}$ & \\
\hline 2015 & $\begin{array}{l}\text { Revista de } \\
\text { Enfermagem } \\
\text { UFPE }\end{array}$ & $\begin{array}{l}\text { Discursos paternos } \\
\text { frente ao nascimento e } \\
\text { hospitalização do filho } \\
\text { prematuro. }\end{array}$ & $\begin{array}{l}\text { Araújo,NM, } \\
\text { Zani,AV. }\end{array}$ & $\begin{array}{l}\text { Apreender os discursos paternos frente } \\
\text { ao nascimento e à hospitalização do } \\
\text { filho prematuro na Unidade de Terapia } \\
\text { Intensiva Neonatal. }\end{array}$ \\
\hline 2016 & $\begin{array}{l}\text { Revista } \\
\text { Latino- } \\
\text { Americana de } \\
\text { Enfermagem }\end{array}$ & $\begin{array}{l}\text { Avaliação da percepção } \\
\text { do cuidado centrado na } \\
\text { família e do estresse } \\
\text { parental em unidade } \\
\text { neonatal }\end{array}$ & $\begin{array}{l}\text { Balbino,FS, } \\
\text { Balieiro,MMFG, } \\
\text { Mandetta,MA } \\
\text { (18) }\end{array}$ & $\begin{array}{l}\text { Avaliar os efeitos da implementação do } \\
\text { método do cuidado centrado no } \\
\text { paciente e família na percepção dos } \\
\text { pais e profissionais de saúde e no } \\
\text { estresse parental. }\end{array}$ \\
\hline 2018 & $\begin{array}{l}\text { Revista } \\
\text { Mineira de } \\
\text { Enfermagem }\end{array}$ & $\begin{array}{l}\text { A humanização em } \\
\text { Unidade de Terapia } \\
\text { Intensiva Neonatal sob } \\
\text { a ótica dos pais. }\end{array}$ & $\begin{array}{l}\text { Noda,LM, } \\
\text { Alves,MVMFF, } \\
\text { Gonçalves,MF, } \\
\text { Silva,FS, } \\
\text { Fusco,SFB, } \\
\text { Avila,MAG. }^{(6)} \\
\end{array}$ & $\begin{array}{l}\text { Compreender os significados de } \\
\text { humanização da assistência sob a ótica } \\
\text { de pais de recém-nascidos internados } \\
\text { em unidade de Terapia Intensiva } \\
\text { Neonatal. }\end{array}$ \\
\hline 2018 & $\begin{array}{l}\text { Revista de } \\
\text { Enfermagem } \\
\text { UFPE }\end{array}$ & $\begin{array}{l}\text { Acolhimento materno } \\
\text { no contexto da } \\
\text { prematuridade / } \\
\text { Maternal reception in } \\
\text { the context of } \\
\text { prematurity }\end{array}$ & $\begin{array}{l}\text { Lelis,BDB, } \\
\text { Souza,MI, } \\
\text { Mello,DF, } \\
\text { Wernet,M, } \\
\text { Velozo,ABF, } \\
\text { Leite,AM }^{(3)} \\
\end{array}$ & $\begin{array}{l}\text { Analisar o acolhimento recebido pelas } \\
\text { mães de recém-nascidos pré-termo } \\
\text { hospitalizados em UTIN de um hospital } \\
\text { amigo da criança. }\end{array}$ \\
\hline 2019 & $\begin{array}{l}\text { Revista Online } \\
\text { de Pesquisa }\end{array}$ & $\begin{array}{l}\text { Percepção das famílias } \\
\text { sobre o acolhimento no } \\
\text { contexto neonatal } \\
\text { durante um processo de } \\
\text { intervenção }\end{array}$ & 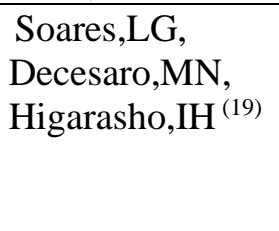 & $\begin{array}{l}\text { Compreender a percepção familiar } \\
\text { sobre o acolhimento no contexto da } \\
\text { assistência em enfermagem neonatal, } \\
\text { antes e após a implementação de um } \\
\text { protocolo de acolhimento. }\end{array}$ \\
\hline
\end{tabular}

Fonte: elaborado pelo autor, 2020.

A partir da análise dos artigos, emergiram três categorias, a fim de facilitar a apresentação e discussão dos resultados: os benefícios do acolhimento à família na UTIN; entraves para a efetivação do acolhimento; e a empatia norteando o processo de acolhimento.

\section{Os benefícios do acolhimento à família na UTIN}

Esta categoria emergiu a partir de os artigos analisados referirem-se aos benefícios em se acolher a família na UTIN. Assim, foi apontado nos artigos, $\mathrm{n}=2(22,22 \%)$, que é importante entender o medo que representa para família a internação, para facilitar o envolvimento dos familiares com a rotina da unidade, contribuindo na aceitação do tratamento intensivo ${ }^{(2,6)}$.

Em outros artigos, $\mathrm{n}=4(44,44 \%)$, foi mencionado, como benefício do acolhimento, que o compartilhamento de anseios e dúvidas envolve mais os familiares no cuidado, além de incentivar a participação nas tomadas de decisão, agindo como facilitadores na adaptação ao ambiente da UTI e aumentando sentimentos de confiança e satisfação ${ }^{(3-4,6,17)}$.

\section{Entraves para a efetivação do acolhimento}

Esta categoria emergiu após serem relatados, em alguns estudos, os entraves para a realização do acolhimento nas UTIN. Após a análise, $\mathrm{n}=3(33,33 \%)$, evidenciaram-se os 
empecilhos descritos pelos profissionais de saúde para a não realização do acolhimento: a rotina de uma unidade de terapia intensiva, por ser muito complexa, exige muito dos servidores para as realizações de demandas técnicas assistenciais e administrativas, sobrecarregando-os e dificultando o desenvolvimento do vínculo e acolhimento aos familiares ${ }^{(2,6,17)}$. Outro fator referido é a falta de sensibilidade dos profissionais, que, ao não acolherem o familiar, fazem com que ele se sinta apenas espectador dos cuidados (6)

Além disso, em alguns artigos, $\mathrm{n}=2$ $(22,22 \%)$, foram relatadas atitudes que resultam em empecilhos ao acolhimento, como a restrição de horários de entrada na unidade ou até mesmo a disparidade de informações recebidas por diferentes profissionais, a falta de escuta qualificada e comunicação não efetiva, com o uso de termos técnicos ${ }^{(6,18)}$.

Outros artigos analisados, $n=5(55,55 \%)$, revelaram o acolhimento às genitoras, porém, no intuito de beneficiar fisiologicamente o neonato internado, como as medidas de amamentação e método canguru, não abarcando os sentimentos maternos e da família na qual o neonato está inserido $(3,6,16,19-20)$

\section{A empatia norteando o processo de} acolhimento

A empatia foi referência em alguns estudos, $n=4$ (44,44\%), como facilitadora da aproximação dos profissionais de saúde junto aos familiares, os quais passam a compreender o momento de fragilidade, bem como a dor do rompimento das expectativas geradas no processo de gestação $^{(2,6,17,19)}$.

Outros estudos, $n=2 \quad(22,22 \%)$, demonstraram que os ensinamentos de cuidados básicos e o ato de trazer o familiar para as ações de cuidados rotineiros, junto com a equipe, auxiliam no desenvolvimento do vínculo familiar e a criança, tornando, consequentemente, a unidade um ambiente menos doloroso e mais acolhedor ${ }^{(17-18)}$.

\section{DISCUSSÃO}

Acolher a família do neonato internado em uma UTIN refere-se ao ato de ofertar ajuda, afeto, apoio e atenção. Prestar assistência integral à criança hospitalizada e sua família compreende partilhar informações e entender os sentimentos de insegurança e medo que cercam a internação. Essas atitudes de acolhimento facilitam o envolvimento dos familiares com a rotina da UTIN e contribui para o processo de aceitação da necessidade do tratamento intensivo ${ }^{(2,6)}$.

Atitudes humanizadas realizadas pela equipe de saúde perpassam o acolhimento, que pressupõe a compreensão do momento de fragilidade em que vive a família, através de uma escuta qualificada, auxiliando na formação de vínculos entre profissionais e familiares. Quando a família é acolhida, ela passa a compartilhar anseios e dúvidas, participa das tomadas de decisão dos cuidados a serem prestados, o que facilita para a melhor adaptação ao ambiente tão temido da terapia intensiva, aumentando os sentimentos de confiança e satisfação ${ }^{(3-4,6,17)}$.

Uma das atitudes de acolhimento referida pelos estudos está em permitir a presença dos familiares desde o momento de admissão do neonato até a alta hospitalar na UTIN, com mínimas restrições de horário de entrada. Quando isso é realizado, permite-se aos familiares a construção do sentimento de pertença à criança, o acompanhamento de forma mais próxima dos cuidados com o neonato, o que reduz sofrimentos 
desencadeados pela separação, como a ansiedade e o medo ${ }^{(17-19)}$.

Nesse sentido, é importante que os profissionais compreendam o momento de vulnerabilidade da família que convive com a criança internada para que haja o desenvolvimento de uma assistência humanizada, pois, a partir do momento em que a família se percebe acolhida e escutada, há uma transformação das suas representações sobre a unidade intensiva, conduzindo-se para que o processo de internação seja menos doloroso.

Outra pesquisa ressalta a importância da comunicação norteando o processo de acolhimento a essas famílias. Refere que, por vezes, os profissionais de saúde passam informações, porém não estabelecem uma comunicação efetiva, o que prejudica a consolidação de vínculos. Possibilitar o esclarecimento de dúvidas e a participação familiar nas tomadas de decisão acerca do tratamento do neonato favorece a aceitação da enfermidade, melhora a relação com os cuidadores e, principalmente, $\mathrm{o}$ desenvolvimento de sentimentos positivos, como confiança, alegria, esperança, facilitando o enfrentamento do processo de internação ${ }^{(2,4,18)}$.

A partir da construção de uma boa relação entre família e equipe de saúde, pautada na escuta qualificada, os sentimentos de tristeza e medo, assim como angústia e desamparo, são substituídos por confiança, alegria, esperança. Tal desfecho é provocado pela sensibilidade dos profissionais e seu envolvimento emocional perante a vivência do internamento de um neonato ${ }^{(17)}$.

Entende-se que o estabelecimento de uma comunicação clara, simples e de fácil compreensão, unida à escuta qualificada e à empatia expressa pelo profissional ao familiar, têm como resultado o despertar de bons sentimentos durante a vivência do processo de doença, confortando a família que passa por essa nova realidade ${ }^{(18,20)}$.

Os benefícios do acolhimento à família são notórios, nos artigos analisados, e vão desde permitir ao familiar o alívio de seus medos e ansiedades, a manutenção dos laços afetivos com o neonato e a participação nos cuidados. Dessa forma, a equipe de saúde tem um papel fundamental para fazer com que o ambiente da UTIN se torne menos hostil e ameaçador, adotando um outro significado para a família.

A internação do neonato em uma unidade de terapia intensiva pode causar impactos negativos no emocional do familiar, pois existe uma idealização social negativa relacionada a este ambiente de internação. Por conta disso, a atuação da equipe de saúde no intuito de minimizar esses danos à família é fundamental. No entanto, muitos profissionais alegam dificuldade em prestar uma assistência ao familiar centrada no acolhimento, devido à sobrecarga de trabalho e pela necessidade em focar nas necessidades de cuidado ao neonato $(2,17)$

Uma UTIN tem sua rotina baseada em protocolos de atendimento técnicos voltados para os cuidados clínicos do paciente internado, que necessita de vigilância constante. A busca pelo reestabelecimento das funções vitais da criança, que demanda tempo e grande esforço dos profissionais, é referenciada como ponto-chave para a não efetivação do cuidado integral ao paciente e família ${ }^{(2,6,20)}$.

O cuidado integral tem como propósito o desenvolvimento de ações que envolvam questões fisiológicas e emocionais do paciente hospitalizado e de sua família, tendo como objetivo compreender os anseios e medos do familiar ao adentrar neste ambiente 
considerado hostil e, por vezes, associado à morte $^{(3,16,19)}$.

Estudos referem que, quando os profissionais não se sensibilizam com $\mathrm{o}$ sofrimento do familiar, este se vê como um espectador dos cuidados a serem prestados à sua criança, e isso intensifica os sentimentos negativos relacionados à internação e a necessidade de adaptação a um ambiente frio e desconhecido. Os familiares, então, passam se sentir na posição de visitantes, que se submetes às normas da unidade sem ter espaço para serem acolhidos nas suas dúvidas e temores ${ }^{(6,20)}$.

Desconhecer as rotinas do serviço e a falta de compreensão das informações repassadas, devido ao uso de termos técnicos utilizados pelos profissionais de saúde, ocasiona o distanciamento do familiar, restringindo suas ações junto ao neonato, evidenciando-se, assim, o protagonismo do profissional de saúde, que se posiciona como detentor do saber ${ }^{(18,20)}$.

As restrições impostas pela unidade e seus profissionais se tornam barreiras para o desenvolvimento da interação entre neonato e familiar. Dificuldades como as relacionadas à restrição de horários de entrada na unidade, ou até mesmo a disparidade de informações recebidas por diferentes profissionais, acarretam a exacerbação de sentimentos como tristeza, desamparo, ansiedade, e culminam na retenção de dúvidas e anseios, por falta de acolhimento da equipe ${ }^{(6,18,20)}$.

Em meio aos estudos selecionados para a análise, a maioria traz os genitores como o foco do acolhimento que deve ser prestado, assim, desconsidera os demais familiares que também auxiliam nos cuidados à criança no período de internamento e após a alta. $\mathrm{Ou}$ seja, o foco em suprir as necessidades biológicas do neonato faz com que os profissionais de saúde não considerem a

família para o cuidado, o que gera distanciamento e, por conta disso, o familiar não se sente confortável em expor suas aflições. Além disso, algumas normas e rotinas da UTIN dificultam a aproximação do familiar com a criança internada, gerando ainda mais sofrimentos.

Ser empático refere-se ao ato de se envolver emocionalmente com o familiar, permitir-se sentir a dor do próximo, se fazer presente e ser apoio diante dos anseios apresentados pelos familiares. Ao ter sua prática baseada na empatia, o profissional de saúde compreende e considera o processo doloroso em que a família se encontra, e, desta forma, conquista a confiança e favorece a construção de uma relação com a família e criança $^{(2)}$.

Ações como convocar o familiar a fazer parte dos cuidados rotineiros com a criança, comunicar de forma clara e ensinar os cuidados básicos, resultam em sentimentos de confiança e felicidade. Perceber a fragilidade da criança e da família por conta da internação em uma UTIN exige dos profissionais sensibilidade, a fim de se estimular o contato do familiar com o neonato, ajudando para que se superem os medos e a desenvolver adaptação emocional para o momento de internação ${ }^{(17)}$.

Outrossim, reconhecer a importância do cuidado integral do paciente e da família é o primeiro ponto para o desenvolvimento da empatia, e isso gera mudanças na forma de cuidar, trazendo a família para perto, em uma posição ativa junto à equipe de saúde e neonato. Paratanto, faz-se necessário que o profissional desenvolva um olhar crítico e sensível para perceber os desconfortos e medos, a fim de proporcionar ao familiar um sentimento de pertença ${ }^{(18)}$.

A identificação de anseios e temores da família pela equipe de saúde da UTIN, desde 
a admissão da criança, faz com que os familiares compreendam a necessidade do cuidado intensivo, contribuindo para a ressignificação do ambiente. Um olhar humanizado que gera ações empáticas favorece a recuperação do vínculo entre a família e o neonato, minimizando sentimentos negativos desencadeados pelo internamento $(6,17,19)$

Ações empáticas e acolhedoras dos profissionais de saúde tornam o período de internação para a família menos doloroso. Equipes de saúde empáticas, através de atitudes acolhedoras, aproximam e inserem o familiar no cuidado e não menosprezam o seu sofrimento, acolhem as suas dúvidas e seus anseios e possibilita uma melhor adaptação à situação vivenciada na UTIN.

Nesse contexto, este estudo contribui para a prática em saúde, pois permitiu entender como o acolhimento aos familiares colabora nos cuidados com os neonatos na UTIN, identificando os benefícios e entraves para a sua realização, assim, os dados desse estudo podem subsidiar as discussões para a implementação de modificações no processo de trabalho, para efetivar o acolhimento aos familiares nas UTIN.

\section{CONCLUSÕES}

Realizar o acolhimento a famílias nas UTIN revelou-se um fator benéfico para a redução de sentimentos negativos relacionados à internação do neonato. A postura acolhedora por parte dos profissionais de saúde possibilita que a família se sinta à vontade para expressar dúvidas, medos e ansiedades e, assim, facilita o enfrentamento do processo de adoecimento de sua criança.

A comunicação eficaz, sensível e clara, juntamente com a escuta qualificada, foram citadas em alguns estudos como uma estratégia facilitadora para o acolhimento. A comunicação sem uso de terminologias técnicas, e que permita a colocação dos saberes populares de cada família, favorece a criação de um espaço para a participação do familiar. Quando o profissional promove uma escuta sensível, juntamente com uma comunicação de qualidade, considerando os anseios da família, acaba por gerar nela sentimentos positivos, como alegria, esperança e confiança frente ao apoio e afeto ofertados.

Por conseguinte, estabelecer o acolhimento desde o momento da internação do neonato faz com que a família se adapte melhor à unidade, auxilia na construção de uma relação de confiança, conhecimento da rotina, participação na tomada de decisão e nos cuidados à criança. Essa postura da equipe resulta de um olhar empático para a família, considerando o seu momento de fragilidade, a fim de que esse período de internação ocorra de forma menos dolorosa.

No entanto, alguns estudos trouxeram entraves para a realização do acolhimento à família pela equipe de saúde, como a sobrecarga de trabalho, algumas normas e rotinas da UTIN e a necessidade de se focar na recuperação do neonato, pautado em um modelo biomédico.

Por conta do número reduzido de estudos desta revisão, alguns aspectos relacionados aos efeitos do acolhimento à família podem não ter sido esclarecidos de modo mais aprofundado, além de muitos artigos limitarem a sua amostra apenas a mães, não abrangendo a família como um todo. Desta forma, reforça-se a necessidade de novos estudos com foco no acolhimento à família; além disso, deve-se estimular a discussão sobre a temática em ambientes acadêmico e assistenciais, a fim de sensibilizar os 
profissionais a considerar a assistência à família como parte do cuidado ao neonato.

Mineira de Enfermagem. 2017. [Acessado em 17 de agosto de 2020] 21.

06- Noda LM, Alves MVMFF, Gonçalves MF, Silva FS, Fusco SFB, Avila MAG. A humanização em unidade de terapia intensiva neonatal sob a ótica dos pais. Revista mineira de Enfermagem. Janeiro 2018. [Acessado em 24 de agosto de 2020] 22.

Silva, ACOC. Cotidiano de mães acompanhantes na unidade de Terapia Intensiva Neonatal. Revista de Enfermagem UEPE online. Julho 2018. [Acessado em 28 de agosto de 2020]. 12(7).

02-Dutra BS, Campolina MB, Arruda TFF, Lisboa AAF, Santana JCB. Significado para as mães de conviver com a internação de um filho em uma unidade de terapia intensiva neonatal. Revista de Enfermagem UFPE on line. Outubro/dezembro 2010. [Acessado em 24 de agosto de 2020] 4(4).

03-Lelis BDB, Souza MI, Mello DF, Wernet M, Velozo ABF, Leite AM. Acolhimento materno no contexto da prematuridade. Revista de Enfermagem UEPE online. Junho de 2018 [Acessado em 24 de agosto de 2020] 12(6).

04- Araújo NM, Zani AV. Discursos paternos frente ao nascimento e hospitalização do filho prematuro. Revista de Enfermagem UFPE on line. Fevereiro 2015. [Acessado em 18 de agosto de 2020] 9(2).

05-Lima VF, Mazza VA, Mór LM, Pinto MNGR. Vivência dos familiares de prematuros internados em Unidade de Terapia Intensiva Neonatal. Revista

07- Ministério da Saúde (BR). Secretaria de Assistência à Saúde. Programa Nacional de Humanização da Assistência Hospitalar. Brasília: Ministério da Saúde; 2011. [Acessado em 22 de novembro de 2020].

Disponível em: http://bvsms.saude.gov.br/bvs/public acoes/pnhah01.pdf

08- Ministério da Saúde (BR). SecretariaExecutiva. Núcleo Técnico da Política Nacional de Humanização. Humaniza SUS Política Nacional de Humanização: a humanização como eixo norteador das práticas de atenção e gestão em todas as instâncias do SUS. Brasília: Ministério da Saúde; 2004. [Acessado em 22 de novembro de 2020]. Disponível em: http://bvsms.saude.gov.br/bvs/public acoes/humanizasus_2004.pdf

09- Ministério da Saúde (BR). Secretaria de Atenção à Saúde. Departamento de Ações Programáticas Estratégicas. Atenção humanizada ao recém-nascido de baixo peso: método canguru. Brasília: Ministério da Saúde; 2011. [Acessado em 23 de novembro em 2020]. Disponível em: bvsms.saude.gov.br/bvs/publicacoes/ Manual_MetodoMaeCanguru.pdf 
10-Crossetti MGO. Revisão integrativa de pesquisa na enfermagem o rigor científico que lhe é exigido. Rev. Gaúcha Enferm. [Internet]. 2012 [acesso em novembro de 2020]; 33(2):8-9. Disponível em: http://www.scielo.br/scielo.php?script=sc i_arttext\&pid=S198314472012000200001\&lng=en.http://dx.d oi.org/10.1590/S198314472012000200001.

11-Mendes KDS, Silveira RCCP, Galvão $\mathrm{CM}$. Use of the bibliographic reference manager in the selection of primary studies in integrative reviews. Texto contexto - enferm. [Internet]. 2019 [Acessado em novembro 2020] 28.

12-Moher D, Liberati A, Tetzlaff J, Altman DG, The PRISMA Group Preferred Reporting Items for Systematic Reviews and Meta-Analyses: The PRISMA Statement. Plos Med. 2009 [Acessado em novembro de 2020] 6(6). Disponível em:https://journals.plos.org/plosmedicine /article?id=10.1371/journal.pmed.100009 7

13-Santos CM da C, Pimenta CA de M, Nobre MRC. The PICO strategy for the research question construction and evidence search. Rev Lat Am Enfermagem [Internet]. 2007 [acesso em 28 de novembro de 2020]; 15(3):508-11. Disponível em:http://www.scielo.br/scielo.php?script =sci_arttext\&pid=S0104$11692007000300023 \& \operatorname{lng}=$ en\&tlng=em

14- Mendes KDS, Silveira RCCP, Galvão $\mathrm{CM}$. Use of the bibliographic reference manager in the selection of primary studies in integrative reviews. Texto contexto - enferm. [Internet], 2019. [acesso em 04 de novembro de 2020]. Disponível em: https://www.scielo.br/scielo.php?script=s ci_arttext\&pid=S010407072019000100602 .

15-Lei no 12.853 de 14 de agosto de 2013. Altera os arts.5o, 68, 97, 98, 99 e 100, acrescenta arts. 98-A, 98-B, 98-C, 99-A, 99-B, 100-A, 100-B e 109-A e revoga o art. 94 da Lei no 9.610, de 19 de fevereiro de 1998, para dispor sobre a gestão coletiva de direitos autorais, e dá outras providências. Diário Oficial da União [Internet]. 2013. Disponível em: http://www.planalto.gov.br/CCIVil_03/ Ato2011-2014/2013/Lei/L12853.htm.

16-Gooding JS, Cooper LG, Blane AI, Franck LS, Howse SL, Bernss SD. Family support and, Family-centered care in the neonatal intensive care unit: origins, advances, impact. Elsevier. Fevereiro 2011. [ Acesado em 1 de setembro de 2020] 35(1).

17- Siqueira MBC, Dias MAB. A percepção materna sobre vivência e aprendizado de cuidado de um bebê prematuro. Epidemiologia serviços de saúde. Janeiro/março 2011. [Acessado em 20 de agosto de 2020] 20(1).

18- Duarte ED, Sena RR, Ditiz ES, Tavares TS, Lopes AFC, Silva PM. A família no cuidado do recém-nascido hospitalizado: Possibilidades e desafios para a construção da integralidade. Texto e contexto enfermagem. Outubro/ Dezembro 2012. [Acessado em 20 de agosto de 2020] 21(4). 
19-Balbino FS, Balieiro MMFG, Mandetta MA. Avaliação da percepção do cuidado centrado na família e do estresse parental em unidade neonatal. Revista LatinoAmericana de Enfermagem. 2016[Acessado em 16 de agosto de 2020] 24.

20-Soares LG, Soares LG, Decesaro MN, Higarasho IH. Percepção das famílias sobre o acolhimento no contexto neonatal durante um processo de intervenção. Revista online de pesquisa. Janeiro/ março 2019 [Acessado em 24 de agosto de 2020] 11(1).

Submissão: 2021-02-03

Aprovado: 2021-03-31 